\title{
The Effect of the Dual Household Registration System on the Population Risk in China
}

\author{
Shiqing Yan \\ College of Urban and Planning, Yancheng Teachers University, Yancheng, China \\ Email: 18360494968@163.com
}

How to cite this paper: Yan, S.Q. (2017) The Effect of the Dual Household Registration System on the Population Risk in China. Open Journal of Social Sciences, $\mathbf{5}$, 147-159.

https://doi.org/10.4236/jss.2017.511011

Received: October 31, 2017

Accepted: November 25, 2017

Published: November 28, 2017

Copyright $\odot 2017$ by author and Scientific Research Publishing Inc. This work is licensed under the Creative Commons Attribution International License (CC BY 4.0).

http://creativecommons.org/licenses/by/4.0/

\begin{abstract}
In order to understand the factors influencing the population risks accurately, this paper analyzes the influence mechanism of China's dual household registration system on population risks. It is found that the China's dual household registration system combined with specific employment, welfare and social security system and family planning policy, and caused the differences of population risks between the urban and rural. The dual household registration system affects the fertility level, the sex ratio at births and mortality, then affecting the urban and rural population size risks and structure risks. The differences of welfare and social security level between the urban and rural residents binding in the dual household registration system affect the size and structure of rural-urban migrants, thus affecting the size risks and structure risks of urban and rural population. The welfare and the urban-rural differences of social security level generate social exclusion, thus the dual household registration system affects the risks of social exclusion in cities.
\end{abstract}

\section{Keywords}

Dual Household Registration System, Population Risk, Urban-Rural Differences, Impact Mechanism

\section{Introduction}

Population risk is one of the important issues of Chinese society at present. Residents have had a significant change in child fertility desire, and the concept of one child has become the mainstream of urban and rural residents in China [1]. China's total fertility rate is much lower than the generation level [2] [3] [4], and the sex ratio at birth is high continuously [5]. With the rapid population urbanization, the urban-rural differential effect of population urban-rural mobility has an important impact on the population structure of areas of origin and those of destination, which have led to national or specific regional population structure 
imbalance and prominent conflicts between human and land, threatening the regional economic development, social stability and so on [6] [7] [8].

Population risk can be divided into population size risk and population structure risk [9] [10]. Population size risk can be divided into two cases. One has a serious negative impact on the social function of specific areas and even population reproduction because of the small number of regional population, which is the intra-system risk within the population system. The other gives rise to the contradiction between population and nature, increasingly acute conflicts between economic and social systems, environmental conditions restricting human survival and development because of the too larger goal population, which belongs to the inter-system risk between population system and environment system. Population structure risks include three categories. The first is the population age structure risk, and the resulting risk of pension and losing single-child. The second category is the risk of population sex structure, and the resulting risk of marriage squeeze and women staying at home violated. The third is the risk of social exclusion of foreign population, and the resulting hatred and opposition of different groups [11].

In January 1958, the Household Registration Ordinance of the People's Republic of China was promulgated and implemented. This ordinance divided all the residents in the country into two types: urban residents and rural residents. Between them, there are significant differences in household registration, employment, welfare and social security, and so on. Thus, this household registration system is called the dual household registration system. China's dual household registration system is an important factor affecting population risk. The important function of the household registration system is the statistics of the population information, while the Chinese dual household registration system recording resident identity information in addition to the statistical function. This household registration system, combined with specific political, economic and social conditions, produces a range of derivative functions, such as restricting the population mobility, political struggle aids, ideological and political education aids and promoting regional economic development [10]. These functions make China's dual household registration system affect the population and population structure of the country or regions, thus affecting the regional population risk and generating the inheritance in time and relevance in spatial.

This article discusses the following problems: firstly, discusses the effect of the dual household registration system on the population size risks; secondly, analyzes the influence of the dual household registration system on the population structure risks; thirdly, gives the influence of the dual household registration system on the temporal and spatial characteristics of population risks. At the end, the conclusion is put forward.

\section{The Effect of the Dual Household Registration System on the Population Size Risk in China}

China's dual household registration system, combined with specific welfare 
systems, social security systems and family planning policy, affects the level of population fertility and the population migration, thus affecting the relationship between the population and the natural, economy and social systems, population size risk and its differences.

\subsection{The Effect of Fertility Levels on the Population Size Risk}

In the 1970s, strict family planning policy was implemented. The effect of the implementation was that the city was better than the rural areas, resulting in the urban population fertility rate was significantly lower than that of the rural areas. To the early reform and opening up in 1981, for example, the national urban women's total fertility rate is 1.39 , rural is 2.91 . In urban areas, one-birth rate of $87.9 \%$, two rate of $10.4 \%$, three rate of $1.3 \%$, four and above accounted for $0.4 \%$. While the rural one-birth rate was $42.0 \%$, two rate of $27.0 \%$, three rate of $14.3 \%$, four rate of $7.5 \%$, five and above accounted for $9.2 \%$ [12]. Obviously, the rural population fertility level was significantly higher than that in urban areas.

In terms of population urbanization, the analysis of panel data from 1980 to 2010 shows that the direct and indirect effect of "urbanization of the registered population on the fertility rate are 1.8 times and 0.8 times of permanent population urbanization" respectively [13]. The fertility rate differences of non-agricultural and agricultural population cause the characteristics of population size changes and the differences of population size risk between urban and rural. The reason for this is that non-agricultural population carry higher welfare and social security than agricultural population, while in violation of family planning policy, non-agricultural population paying higher economic costs and opportunity costs. It can be seen that the household registration system has different effects on the size risk of the urban and rural population by affecting the birth behavior of the non-agricultural and the agricultural population.

\subsection{The Effect of Mortality Rate on the Population Size Risk}

China's dual household registration system, combined with the specific employment system, welfare system and social security system, generates the significant differences in the living standards, employment, labor protect, health care conditions between urban and rural residents, leading to the mortality rate difference of urban and rural residents.

The combination of the dual household registration system and the medical security system has resulted in a large regional disparity in the quantity, quality and accessibility of medical and health resources between urban and rural areas. For example, in 2006, China's urban and rural health costs were 658.131 billion yuan and 322.62 billion yuan [14]. The city has a sound medical and health conditions and social security system, the government, units and individuals tripartite investment, sharing the occurrence of medical and health burdens. In rural areas, the degree of medical social security is low. Before the implementation of new rural cooperative medical care, rural residents lacked medical security and the capacity to pay, resulting in urban and rural differences on mortality rate. 
Similarly, there are differences of the cost of health care in different regions, which have an impact on the mortality of residents in different regions. According to the results of the third national death survey, the spatial difference of mortality rate in China is obvious. The mortality rate of rural areas is 19 percentages higher than this of the cities. The rate of cities in the middle and west are 22 and 25 percentage higher than those in the eastern cities respectively. The rate of rural areas in the middle and west are 13 and 15 percentage higher than those in the eastern rural respectively [15].

The differences in the employment of urban and rural residents, caused by the combination of the dual household registration system and the employment system, have led to significant differences in the injury risks and living environment of urban and rural residents, thus affecting their mortality rate. In the cause of death, the percentage of injuries that have been hurt can explain the problem well. According to the survey, from 1990 to 1997, the number of people who injured was $6.2 \%$ to $7.1 \%$ of the total number of deaths in the city, while rural residents in the same period accounted for $10.7 \%$ to $12.0 \%$ of the total number of deaths, which illustrates that the difference in working environment of urban and rural residents related to the household registration system is the most important cause of this phenomenon [16].

\subsection{The Effect of the Characteristics of Population Migration on the Population Size Risk}

The new China's household registration system is called the dual household registration system, because urban residents and rural residents are labeled nonagricultural accounts and agricultural accounts, which gives the corresponding benefits to residents according to the nature of the account, affecting the number of migrants directly or indirectly, leading to a certain degree of isolation of non-agricultural and agricultural population. As a result, China's dual household registration system has a certain population risk effect. China's dual household registration system has experienced two stages: isolation dual household registration system and infiltration dual household registration system [10]. The population risk effect and its formation mechanism of the dual household registration system in the two stages are difference.

In the first stage, the combination of household registration system and welfare and social security system limit the urban-rural population migration, through administrative measures and welfare exclusion, thus affecting the regional population size risk. As the household registration system restricting the flow of population, China's urban population growth is slow, and even appeared negative growth stage for many years. In 1958, the urban population was 107.21 million, and the urbanization level reached $16.2 \%$. In 1959, the urban population increased to 12.31 million, the urbanization rate was $18.4 \%$. In 1960, the urban population was 130.73 million and the urbanization rate was $19.7 \%$. In 1961 , China conducted national economy adjustment, reduced urban workers and urban population decreased. In 1963, the urban population was only 11.646 million, 
a decrease of 14.27 million compared with 1960, and the urbanization level dropped to $16.8 \%$. Despite the increase in urban population after 1964 and the level of urbanization increased to $18.4 \%$, China's urbanization rate was consistently no more than 18.0 percent in 1965 and even reduced to 17.1 percent in 1972, during the 13 years between 1966 and 1978. Obviously, when China's dual household registration system restricting the flow of rural population, it avoided the population size risk caused by large population increase effectively. However, in rural areas of specific areas, the drastic increase of rural population, the aggravating contradictions between people and the environment, and the contradictions expanded to the social field, have resulting in a series of social risks caused by the increase of population.

In the second stage, the household registration system alleviates the risk of urban population size risk through the welfare exclusion. The welfare exclusion of the household registration system affects the number of the bring-along migration by education, health care, housing, minimum security, and so on. In July 2005, the survey of the status of migrant population and service needs in Shanghai Min-hang District showed that the probability of migratory children promoted by migrants staying in Shanghai less than six months is only $21.0 \%$; the probability promoted by migrants staying in Shanghai more than 10 years reach to $56.2 \%$. For all the floating population, regardless of the length of time in Shanghai, the probability of promoted migration of the elderly are not high, fluctuating between $10 \%-16 \%$ [17]. The exclusion of welfare and social security affects the number of bring-along migration, thus affecting the population size risk.

In the welfare exclusion in the city, residential exclusion is compelling. Due to housing consumption accounted for a large proportion of wages and its one-time investment is very large, the effect of residential exclusion is obvious. The security system, for example, launched by Shanghai in 2009, provides registered population and introduced talent with low-rent housing, a total property rights protection housing (affordable housing), public rental housing and collection and resettlement housing (relocation housing), with the premise of having Shanghai account, or the introduced talent in Shanghai. Therefore, the city is like a castle, the rescue system is like a castle, people outside rely on the account, economic means to come. If not introduced talent, the foreign population cannot enjoy housing security, and difficult to foothold in the city because there is no Shanghai account. Some sociologists believe that residential exclusion may be becoming a major means of government to reduce population pressure [18]. Obviously, the household registration system reduces the pressure on urban population through the housing exclusion, playing a certain role in easing the population size risk.

\section{The Effect of the Dual Household Registration System on the Population Structure Risk in China}

China's dual household registration system, combined with the specific welfare 
and social security system and family planning policy not only affect population size risk, but also play an important role in changing the regional population structure, thus influencing China's population structure risk and its urban and rural differences.

\subsection{The Effect of Fertility and Mortality Rate on the Population Structure Risk}

In the early 1980s, China's family planning policy tightened from the late, thin, less to one child. Influenced by the dual household registration system in China, the significant differences in employment, welfare and social security between urban and rural residents lead to the motive force and cost of birth different, thus significant difference of fertility rate between urban and rural areas. This difference has important influence on China's population structure risk and its difference in urban and rural areas.

The household registration system affects the age structure risk of the household population by influencing the relationship between the birth rate and the mortality rate. Under the influence of the dual household registration system, the effect of family planning policy is much better than that in rural areas, so that the rural population birth rate is higher than that of the city. The welfare of the urban household registration is better than that of the rural household, which is an important influencing factor that the rural mortality rate is higher than that of the city. As a result, the rural population birth rate, mortality and natural growth rates are higher than the city. In 1998, for example, the birth rate of the urban population was $13.67 \%$, the mortality rate was $5.31 \%$, the natural growth rate was $8.36 \%$, the birth rate of the rural population was $17.05 \%$, the mortality rate was $7.01 \%$, the natural growth rate was $10.04 \%$, indicators in rural areas are higher than that of urban [19]. Demographic changes in urban and rural areas will inevitably lead to the differences in the pension risk of household population in urban and rural areas [20] [21]. According to household statistics, the proportion of urban elderly dependency is higher than that of rural areas and the pension risk is large in urban areas.

Household registration system leads to the urban and rural difference in the risk of losing single-child, through affecting the total fertility rate. The implementation difference of one-child family planning policy caused by China's dual household registration system, lead to the risk of losing single-child different in urban and rural areas. Based on the 1990 and 2010 census data in China, from the broader statistical caliber, the cumulative number of the country's single-child died or losing single-child family reached 100.3 million in 2010. From the more stringent statistical caliber, the cumulative number of the country's single-child died or losing single-child family reached 64.45 million in 2010. However, the urban-rural difference of total fertility rate caused by the implementation difference of family planning policy, makes the proportion of single-child families in urban and rural families different. In 1998, for example, the national total fertility rate of 1.8 or so, estimated about 2.1 in rural areas, the city 
is about 1.2 , the rural fertility rate is much higher than the city. As the number of agricultural accounts is much larger than non-agricultural accounts, the number of single-child in the agricultural population is slightly higher than that of non-agricultural population. It is estimated that between 5 and 30-year-old single-child agricultural accounts of about 63.8131 million, accounting for $53.3 \%$ of the total; non-agricultural accounts of about 5586.25 million, accounting for $46.68 \%$ of the total [22], thus the absolute number of losing single-child families may be slightly larger than that in city. According to the percentage of losing single-child families in all families, the risk of losing single-child in urban families is much higher than in rural.

\subsection{The Effect of the Sex Ratio at Birth on the Population Structure Risk}

The combination of the dual household registration system and the employment system, the welfare system and the social security system will affect the urban and rural residents' cost of violating the family planning policy, thus the urban-rural differences in implementation effect of the family planning policy. Under the influence of the traditional thoughts of son preference, the difference of gender ratio between urban and rural population is significant, which affects China's population gender structure risk and its urban-rural differences.

First, after the implementation of the one-child policy in the early 1980s, the sex ratio at birth was increasing. The sex ratio at birth was 1980.3, 107.0, 107.2, $107.8,108.3,112.2,112.2$ and 110.9 , from 1980 to 1987 , respectively. It can be seen that the sex ratio at birth has increased rapidly since 1985 [23]. Second, the sex ratio at birth increases with the increase in childhood and the passage of time. From the point of view of child, between 1980 and 1988, the birth sex ratio of the second, the third, the fourth or the fifth children were 4.706, 8.009, 10.560 and 10.628 higher than the average sex ratio of the first child. From the point of view of time, after 1980, the sex ratio of the third, the fourth (except 1981 and 1983) and the fifth children were higher than the normal level. After 1984, the sex ratio at birth of the second child also increased significantly, and the average birth sex ratio increased by 1.2 every year [24]. Thirdly, the increase in the sex ratio at birth is due to the increase in rural population. From 1980 to 1987, the urban sex ratios were 107.7, 107.6, 110.2, 103, 10, 10.4, 104.2, 107.8 and 103.8, while the rural areas were 106.3, 106.7, 105.8, 107.4, 108.5, 112.7, 110.5 and 112.4 [22]. Although the sex ratio in the urban birth population fluctuated, it did not rise. After the implementation of the family planning policy, the rural population sex ratio gradually increased. Fourth, the increase in the sex ratio at birth in rural areas is due to the increase in the sex ratio of births against the family planning policy. From 1980 to 1987, the rural sex ratios at birth were 104.63, $105.25,102.76,106.46,102.41,109.14,104.34$ and 108.75, which did not increase. The rural sex ratio at birth against the policy at the same time was 107.64, 107.81, $108.30,108.21,114.48,116.35,117.49$ and 116.56 , which increased rapidly [23]. Fifth, boys or girls have an important impact on the sex ratio of subsequent birth 
of rural women. In 1989, for example, in the rural female household with boys, the sex ratio of the second child was 138, the third was 188 , the fourth was 182 and the fifth child was 204. In the rural female household with a boy, the sex ratio of the second child was 101, the third is 108 , the fourth and the fifth child was 128. It can be seen that rural women of childbearing age are so eager to boys that giving birth to two or more children [24].

The above facts illustrate two issues: First, after the implementation of the one-child policy, the increase of the sex ratio at birth in rural areas has led to an increase in the sex ratio at birth, the widening gap between urban and rural births, and the resulting sex structure risk and its urban-rural differences increasing continuously. Second, the household registration system played an important role where the benefits and social security of rural households is far less than urban accounts. On the one hand, farmers can only rely on raising sons to provide for their old age, thus requirement of boys is much larger than urban residents. On the other hand, the cost of against the one-child policy is much lower than that of urban residents, thus rural residents are more likely to violate the family planning policy.

\subsection{The Effect of the Characteristics of Population Migration on the Population Structure Risk}

China's dual household registration system, combined with welfare and social security System affects the structural characteristics of urban-rural migration. From the point of view of employment migration, the intensity of urban-rural migration has increasing in the infiltration dual household registration system stage. The dual household registration system is associated with the welfare and social security system, which strengthens the demographic characteristics of employment migration. Welfare system restricts the phenomenon of men to bring-along migration [17], thus the advantage of young and middle-aged men more obvious in the employment migration. The fifth national census data show that sex ratio of employment migration population is 134.8 , and migrating flows more than 20 million are male [25], making the city resident population sex ratio increased and rural resident population sex ratio decreased. In the context of a continuous increase in the sex ratio of the population, employment migration increases the risk of urban gender structure. In addition, because the migrant workers are the main of city foreign population, the proportion of young people was significantly higher than the urban household population [6]. In the context of the aging of the population, the inflow of young and middle-aged people has a positive effect on alleviating the risk of urban old-age care, but exacerbating the process of aging and the depth of aging in rural areas.

From the perspective of marriage migration, the main feature is that women migrate to the areas with higher level of welfare and social security from the areas with low level of welfare and social security. Much urban public welfare is attached to big city household registration, and thus the phenomenon of marriage for the account is very common. Studies in Shanghai show that welfare 
gradients are significant from agricultural household registration to urban household registration. Although there are differences in the internal and external welfare within the city, there are still some advantages over the rural areas. Even if not completely for the household registration to marriage, the city's inherent public service is the village cannot compete. In order to obtain urban public welfare, the marriages take marriage as an exchange tool to obtain the identity of the city people [18]. Marriage migrants are mainly from rural to urban areas. According to the data of sixth census in Huangpu District in Shanghai, the agricultural households accounted for $67.9 \%$ of marriage migration in Shanghai, and the agricultural households accounted for $68.2 \%$ of the inter-provincial marriage migration [26]. The movement of the female population migrating from rural to urban, alleviates the risk of marriage squeeze in urban, but increases the risk of the squeezing in rural areas, especially the less developed villages.

\subsection{The Effect of the Difference of Welfare on the Social Exclusion Risk}

A large number of rural labors migrate to the city in the infiltration dual household registration system stage. However, the social exclusion to migrant workers without local city account, forma strong institutional force preventing migrant workers into urban society, which directly or indirectly affects the social exclusion of migrant workers in all aspects of economy, politics, social networks, culture, social security and education [27]. Based on this, migrant workers are excluded by urban residents because of their employment, income levels, living habits and other reasons. Urban residents' prejudice and discrimination are rooted in urban and rural division system, but the psychological bias has a certain stability, which can play an independent role in the gradually collapsing system and maintain the migrant workers exclusion in culture and network [28]. China's dual household registration system has become the system root of migrant workers' social exclusion in the city.

Similarly, the dual household registration system, combined with the rural land contract system and other systems, generate social exclusion to urban residents without local accounts in rural areas. This exclusion is mainly manifested as economic exclusion, they are excluded from the rural land contract, homestead welfare, rural collective economic organizations and other welfare system. In the urban suburbs of economically developed areas, the collective economic organization dividends are important, due to the high value of homestead.

\section{The Effect of the Dual Household Registration System on the Relevance of Population Risk in China}

China's dual household registration system, combined with the specific employment system, welfare system and social security system, make parents' household registration status influencing their children's status, thus making the intergenerational relevance of population risk and geographical relevance of 
population size and structure caused by population migration. Therefore, we explore the impact of population risk relevance by China's dual household registration system from the two aspects of time and space.

\subsection{The Effect of the Dual Household Registration System on the Intergenerational Relevance of Population Risk}

China's dual household registration system has a citizenship function. The nature of the child's account is decided by the mother's nature of the account. Once the nature of the account determined, it is difficult to change. Non-agricultural accounts carry higher levels of benefits and security than agricultural accounts. Therefore, the nature of parents' account becomes an important factor influencing children's development and social mobility. Non-agricultural accounts have better benefits and social security levels, favoring the growth of young people, thus urban youths tend to have better opportunities than rural youth. Besides, research shows that the account affects joining the party, the level of economic income, occupation, etc. [29]. In addition, the impact of different accounts on population risk has been described earlier. Therefore, under the influence of China's dual household registration system, population risk has a certain degree of intergenerational transmission.

\subsection{The Effect of the Dual Household Registration System on the Regional Relevance of Population Risk}

The combination of the dual household registration system and the welfare and social security system affects the characteristics of the migrant population, so that the population size and structure of areas of origin and areas of destination are closely related to each other, leading to the spatial relation of population risk. For example, the employment migration whose main body are young men, van ease urban population aging and the risk of urban pension, but exacerbated the aging process and the depth of aging and aggravated the risk of pension in the rural areas. At the same time, large inflow of young men to the city increase the risk of urban population gender structure, leading to the risk of women staying at home violated and children education risk. Marriage migration with young women as the main body, can mitigate the risk of marriage squeeze in urban and developed areas, but increases the risk of rural marriage squeeze in rural areas, especially in underdeveloped areas.

\section{Conclusions}

China's dual household registration system was set up in the background of very backward economy and enormous pressure of industrialization. This household registration system has a positive effect on the stability of urban economy and society and the promotion of industrialization, and has the function of changing the risks of national survival to the population risks. With the continuous development of economy and industrialization, the population risk in China caused by the dual household registration system is gradually emerging, and the 
unitary reform of the dual household registration system has become necessity of the times.

China's dual household registration system has a population risk effect. China's dual household registration system affects the population size risk by affecting the population birth rate, mortality and migration characteristics. It affects the population structure risk by affecting the natural population growth rate, the sex ratio at birth, the demographic structure of migrants and the social status of urban and rural household. Through intergenerational transmission, regional association and so on, China's dual household registration system affect the space-time connection of population risk. To study China's dual household registration system and its unified reform, we must accurately grasp the population risk effect and its changing trend, and try to develop scientific and reasonable household registration system reform policy services.

The population risk effect of China's dual household registration system is the result of multiple systems. The population risk effect is caused by the combination of the dual household registration system and the employment system, the welfare system and the social security system, where urban and rural areas are divided. In the course of the formation of the population risk effect, China's dual household registration system has played a function of citizenship and provided a platform for other welfare and social security system to play a role. To study the population risk effect of the dual household registration system in China, it is necessary to know the practical effect of the household registration system.

China's household registration system reform makes the spatial difference of population risk effect more significant. China's dual household registration system has a wide range of changes and significant regional differences in the process. The combination of household registration system and welfare and social security system, has different influence on the population size risk, structural risk, and the time-space correlation of population risks. To study the population risk effect of the dual household registration system in China, we must analyze in depth according to the actual situation of different regions.

\section{Acknowledgements}

This research was partly supported by the project of philosophy and social science research in the colleges and universities in Jiangsu province (No. 2016SJB840022).

\section{References}

[1] Tang, Z.Y. and Guo, Z.Z. (2012) Level of Economic Impact Analysis of Fertility Desire. Population \& Development, 3, 27-33.

[2] Morgan, S.P., Guo, Z.G. and Sarah, R.H. (2009) China's Below-Replacement Fertility: Recent Trends and Future Prospects. Population and Development Review, 3, 605-629. https://doi.org/10.1111/j.1728-4457.2009.00298.x

[3] Peng, X.Z. (2011) China's Demographic History and Future Challenges. Science, 333, 581-587. https://doi.org/10.1126/science.1209396 
[4] Yang, F. and Zhai, Z.W. (2012) Exploration and Establishment of the Chinese Model of Demographic Transition. Population Research, 1, 25-33.

[5] Yuan, X. and Hu, Y.L. (2010) The Situation, Characteristics and Countermeasures of the High Sex Ratio at Birth in China. Population and Family Planning, 6, 4-5.

[6] Zhu, B.S. (2008) The Difference Characteristics of Urban Migrant Population and Related Policies. Journal of East China Normal University (Philosophyand Social Science Edition), 1, 48-53.

[7] Wang, Z.M., Wang, C.Z. and Zhang Q. (2015) Population Ageing, Urbanization and Housing Demand. Journal of Service Science and Management, 8, 516-525. https://doi.org/10.4236/jssm.2015.84052

[8] Lu, L., Zhang, Y. and Luo, T.T. (2014) Difficulties and Strategies in the Process of Population Urbanization: A case Study in Chongqing of China. Open Journal of Social Science, 2, 90-95. https://doi.org/10.4236/jss.2014.212013

[9] Guo, X.Y. (2010) Research on the Population Development and the Risk Control in Big Cities. Lanzhou Academic Journal, 3, 115-119.

[10] Yan, S.Q. (2012) On the Evolution and the Reforming Paths of China's Household Registration System. Doctoral Dissertation, East China Normal University, Shanghai.

[11] Yan, S.Q. (2015) Study on the Impact of Industrial Cluster Characteristics on the Risks of Senior Life: A Case Study of the Poplar Industry Cluster in the North of Jiangsu Province. Journal of Inner Mongolia Normal University (Philosophy and Social Science Edition), 5, 67-72.

[12] Zhang, Y.Z. (1987) The Difference of Family Function between Urban and Rural Areas and Its Influence on Population Fertility Rate. Social Sciences in Ningxia, 3, 59-63.

[13] Ge, Y.X. (2015) How to Urbanization Affect Fertility Rate in China. Population Journal, 3, 88-101.

[14] Ministry of health of People's Republic of China (2008) China Health Statistics Yearbook. Peking Union Medical College Press, Beijing.

[15] Chai, Y.Y., Zhang, X.Y., Ye, E.K., et al. (2010) Analysis of the Differences in Mortality and the Influencing Factors between Urban and Rural Residents in China. Modern Preventive Medicine, 21, 4070-4072.

[16] Cao, W.H., Wu, T. and An, T. (2000) Study on the Mortality of Injury in Chinese Population in Urban and Rural Areas From 1990 to 1997. Chinese Journal of Epidemiology, 5, 327-329.

[17] Zhang, W., Miao, Y.P. and Yan, S.Q. (2009) Characteristic Research on "Bring-Along Migration” of Floating Population in Big Cities' Suburb. Human Geography, 5, 36-41.

[18] Residential Exclusion: The Main Means of the Government to Reduce the Population Pressure? http://www.banyuetan.org/chcontent/sz/szgc/2015916/151094.html

[19] Zhang, J.W. (2000) Differences of Urban and Rural in Population Transition and Policy Options in China. Population Science of China, 4, 46-50.

[20] Rosa, C. and Pereira, E. (2017) Evolution of the Number of Students in Elementary and Secondary School in Portugal a Population Ageing. Open Journal of Social Science, 5, 112-127. https://doi.org/10.4236/jss.2017.57008

[21] Chen, C.Y. (2017) Analysis on Hong Kong's Current Medical Service under the Aging Population. Open Journal of Social Science, 5, 31-37. https://doi.org/10.4236/jss.2017.54003 
[22] Wang, G.Z. (2013) Study on the Total Mortality and Trend of the Only Child of China. Chinese Journal of Population Science, 1, 57-65.

[23] Xu, Y. and Guo, W.M. (1991) To Explore the Status of Sex Ratio at Birth of the Chinese and Related Issues. Population \& Economics, 5, 9-13.

[24] Gao, L. (1993) Analysis of Sex Ratio at Birth of the China Population. Population Research, 1, 1-6.

[25] Ding, J.H., Liu, Z.Y., Cheng, D.M., et al. (2005) Areal Differentiation of Inter-Provincial Migration in China and Characteristics of the Flow Field. Acta Geographica Sinica, 1, 106-114.

[26] Guo, Y.C., Ding, J.H. and Huang, Y. (2014) Gradient Characteristics of Urban and Rural Marital Migration in Big Cities. Urban Problem, 8, 95-100.

[27] Jiang, L.H. and Hu, J.C. (2006) Social Exclusion and the Marginalization of Status of the Peasant Workers. Journal of Huazhong University of Science and Technology (Social Science Edition), 6, 112-116.

[28] Lu, Y.L. (2008) Does Hukou Still Matter? The Household Registration System and Its Impact on Social Stratification and Mobility in China. Social Sciences in China, 1, 149-162.

[29] Nor, H.R., Azhar, N.S. and Ibrahim, K. (2105) Population Restructuring: The Impact on Poverty Eradication in Malaysia and Medina. Open Journal of Social Science, 3, 65-79. https://doi.org/10.4236/jss.2015.36013 